\title{
QUALITY OF OPERATIVE NOTES FOR LAPAROSCOPIC CHOLECYSTECTOMY: ARE THEY USEFUL?
}

\author{
Amit Kumar1, Neel Kamal Gola², Devendra Kumar Shiwach ${ }^{3}$ \\ ${ }^{1}$ Lecturer, Department of Surgery, Kantipur Dental College Teaching Hospital and Research Centre, Kathmandu. \\ ${ }^{2}$ Assistant Professor, Department of Surgery, Rama Medical College Hospital and Research Centre, Hapur, Uttar Pradesh. \\ 3 Assistant Professor, Department of Surgery, Rama Medical College Hospital and Research Centre, Hapur, Uttar Pradesh.
}

\section{ABSTRACT}

\section{AIM}

The operative note describes the indication and steps of surgery performed forms the base of surgical care. It is the repository of perioperative events, which are queried in case of adverse events for research activities and sometimes in medicolegal cases. In order to be useful, it must be objective, complete, and reflect the operation it is supposed to describe. This study evaluates the quality of operative notes in our setup.

\section{METHODS}

One hundred two charts of patients undergoing laparoscopic cholecystectomy in three hospitals during the period August to November 2015 were evaluated against Good Surgical Practice recommended by Royal College of Surgeons of England and with a standard format for laparoscopic cholecystectomy, which emphasised intraoperative details with the intention of preventing operative mishaps.

\section{RESULT}

Of the 102 patients' record, 32\% were deficient regarding multiple parameters. Only $58(56.85 \%)$ of the records mentioned critical view of safety. Eighty two (80.3\%) of patient's notes mentioned the insertion of laparoscopic ports under vision and in 90 $(88.2 \%)$ cases the description of dissection and clipping of cystic duct or artery was present. The duration of operation was mentioned in 67 charts and presence or absence of drain was noted in 81 (79\%) operative records. Sixty four (62\%) charts lacked any mention of DVT prophylaxis and $43.3 \%$ lacked notes regarding estimated blood loss. Involvement of residents in the operation were more likely to be detailed in their operation note. Video record of thirty three operations was present.

\section{CONCLUSION}

All the charts reviewed had mention of names of operating surgeons, anaesthesia, diagnosis, and postoperative instructions. The missing information like details of operation like critical view of safety, port removal and closure, a procedure specific form, or electronic charting with prompts can improve the quality of notes.

\section{KEYWORDS}

Critical View of Safety, Documentation, Laparoscopic Cholecystectomy, Operation Note.

HOW TO CITE THIS ARTICLE: Kumar A, Gola NK, Shiwach DK. Quality of operative notes for laparoscopic cholecystectomy: are they useful?.Evolution Med. Dent. Sci. 2016;5(62):4360-4364, DOI: 10.14260/jemds/2016/995

\section{INTRODUCTION}

Laparoscopic cholecystectomy is one of the commonest operations performed worldwide and it is also one the most frequent procedure involved in medicolegal cases.[1] The current operative reports vary widely in content and many a times omit important elements.[2] Intraoperative surgical technique has significant effect on postoperative morbidity and mortality.[3,4] Analysis of operative technique and any retrospective enquiry is difficult as there are wide variations in information noted down in the operative records. Din et al. recommended use of aide-memoire to improve the quality of operative notes in orthopaedic surgeries.[5]

In our hospitals even where billing and admissions are computerised; patient's records and most follow up records are handwritten and present in paper forms only.

Financial or Other, Competing Interest: None.

Submission 18-02-2016, Peer Review 02-06-2016,

Acceptance 07-06-2016, Published 03-08-2016.

Corresponding Author:

Amit Kumar,

Department of Surgery,

Kantipur Dental College Hospital,

Basundhara, Kathmandu, Nepal.

E-mail:dramitkr@hotmail.com

DOI: 10.14260/jemds/2016/995
This operative record is present alongside other admission details, preoperative workup, and postoperative follow up information in a single file binder collected in the medical records department and difficult to access as well. Such operative notes and the postoperative instructions and observations are vital for review of operation and future planning.

Operation notes are crucial in cases of litigations, audits, retrospective research, observations, or for administrative planning. Some hospitals do keep computerised records and videos record of the operation, but this is not universally applicable. Even in such instances many aspects of the decision making and events may not be stored.[2]

Despite the operative note and perioperative orders being such a critical component of patient care; there are no formal instructions regarding this in most institutions. In our country, there are no formal standards for the components of operation note. The lack of standardised operative note and items included in the note became apparent when we were undertaking an audit of our laparoscopic cholecystectomy. Unlike the Royal College of Surgeons England or Dutch standard, there are no basic standard recommendation in India or Nepal.[6,7] In this study, we evaluated the status of operative record keeping in patients undergoing laparoscopic 
cholecystectomy in different units of surgery in two teaching hospitals and a general hospital. Laparoscopic cholecystectomy is a commonly performed high volume operation with a fairly standardised description of steps needed and deviations or mishaps leading to complications can have devastating consequences. In our review of patient's records of those undergoing cholecystectomy, we encountered a number of deficiencies while trying to gather data. This study is conducted to study the quality of operative report for laparoscopic cholecystectomy and find ways to improve these records.

\section{MATERIALS AND METHODS}

We compared 102 cases of operative notes following cholecystectomy in two teaching and a general hospital. All laparoscopic cholecystectomies conducted in the three hospitals between August 2014 and November 2014 were retrospectively reviewed. Permission was sought and granted from Institutional Review Board for the study.

\section{Development of a Standard Report}

Authors surveyed and conducted a literature review regarding what information constitutes an important part of a standard laparoscopic cholecystectomy. A list of operative details was identified that the participating surgeons agreed should be the minimum documentation in laparoscopic cholecystectomy surgery operative report. This final list is shown in table 1. Presently, paper proforma-based notes is used. This has multiple subheadings with space for free text writing, which forms part of the patient record file. All the selected operations notes were studied and the data extracted matched against the standard note. Any deficiencies in the operation notes were noted and tabulated in a Microsoft excel file and further compared and analysed. The recommendations of Good Surgical Practice 2014 Guidelines regarding operative note is summarised in table 2.[6]

\section{RESULTS}

The patient characteristics and the indications for surgery is illustrated in Table 3. In total, 102 patients were included - 30, 42 , and 30 from three hospitals respectively marked as A, B, and C. Eighty three of the 102 patients were females (81.3\%). Table 3 shows the compliance of various notes with a standardised item chart.

1. Demographic data and time and date were present in all notes.

2. Names of participating surgical and scrub team workers was present in $>95 \%$ of notes. In some places, the names were not legible and notes (4, 1, 1 respectively) left the scrub nurse blank. The data was present in some other place in patient file like the anaesthesia chart.

3. The indication of surgery and surgery performed was noted in all patients.

4. The type of anaesthesia and starting position was also noted in most notes. Hospital A, B, and C as 28,41 , and 27 (92\%, 95\%, 89\%) respectively.

5. The insertion of first port or creation of pneumoperitoneum was described in $93.3 \%$ of A, $100 \%$ of B, and only $86 \%$ of C. Initial description of gallbladder and liver was present in $60 \%$ of A, $36(85.7 \%)$ of B, and $60 \%$ of C. Other findings and their description as seen in tabulated in Table 2.
6. Presence of drain was mentioned in almost all of the cases in all three hospitals where it was inserted. Absence of drain was mentioned in $30 \%$ of A, 21 (70\%) of Hospital B, and $0 \%$ in Hospital C.

7. There was one patient having bile leak for six days, which required ERCP and stenting for the same. The anatomical difficulty was mentioned in the operative note, but no details were present.

\begin{tabular}{|c|c|}
\hline $\begin{array}{l}\text { 1. Operation Planned: } \\
\text { 2. Operating and Anaesthesia } \\
\text { Team }\end{array}$ & Date and time \\
\hline 2. Patient data & $\begin{array}{l}\text { Name, Age, Sex, } \\
\text { Hospital Number }\end{array}$ \\
\hline 3. Indication & $\begin{array}{c}\text { Biliary colic } \\
\text { Cholecystitis } \\
\text { Gallstone pancreatitis } \\
\text { Cholangitis } \\
\text { Acalculous cholecystitis } \\
\text { Other }\end{array}$ \\
\hline $\begin{array}{l}\text { 4. DVT Prophylaxis } \\
\text { 5. Preoperative Antibiotics }\end{array}$ & $\begin{array}{c}\text { Pneumatic compression } \\
\text { stockings } \\
\text { Heparin } \\
\text { Stockings and Heparin } \\
\text { Any other } \\
\text { Specify Antibiotic }\end{array}$ \\
\hline 6. Abdominal Entry: & $\begin{array}{l}\text { Hassan } \\
\text { Veress Needle } \\
\text { Other }\end{array}$ \\
\hline $\begin{array}{l}\text { 7. Gallbladder Appearance } \\
\text { Size and Wall thickness }\end{array}$ & $\begin{array}{c}\text { Normal } \\
\text { Inflamed } \\
\text { Scarred (previous } \\
\text { inflammation) } \\
\text { Gangrenous } \\
\text { Other }\end{array}$ \\
\hline $\begin{array}{l}\text { 8. Condition of Calot's area } \\
\text { and adhesiolysis }\end{array}$ & $\begin{array}{c}\text { None } \\
\text { Mild } \\
\text { or severe - how lysed } \\
\text { Cautery/blunt dissection }\end{array}$ \\
\hline 9. Critical View of Safety & Mentioned or not \\
\hline $\begin{array}{l}\text { 10. Any anatomical } \\
\text { abnormality }\end{array}$ & Mentioned or not \\
\hline $\begin{array}{l}\text { 8. Conversion to Open Yes or } \\
\text { No Reason if converted }\end{array}$ & $\begin{array}{c}\text { Surgical complication (e.g. } \\
\text { Bleeding, CBD injury) } \\
\text { Technical problems (e.g. } \\
\text { Inability to complete) } \\
\text { Anatomic abnormality } \\
\text { CBD exploration } \\
\text { Malignancy suspected } \\
\text { Other }\end{array}$ \\
\hline $\begin{array}{l}\text { 9. Cystic Artery Ligation: } \\
\text { 10. Cystic Duct Ligation: }\end{array}$ & Number of Clips \\
\hline $\begin{array}{l}\text { 11. Bile Spillage or Gallstone } \\
\text { Spillage: }\end{array}$ & $\begin{array}{l}\text { Yes or No. If yes - were } \\
\text { they recovered }\end{array}$ \\
\hline 12.Extraction of Gallbladder & Port and method \\
\hline 1. Drain insertion & If not, is it mentioned? \\
\hline $\begin{array}{l}\text { 13. Securing haemostasis and } \\
\text { port removal under vision }\end{array}$ & Position and suture used. \\
\hline \multicolumn{2}{|c|}{$\begin{array}{c}\text { Table 1: Showing the Standard Information to be } \\
\text { Present in Laparoscopic Cholecystectomy Operative } \\
\text { Note }\end{array}$} \\
\hline
\end{tabular}




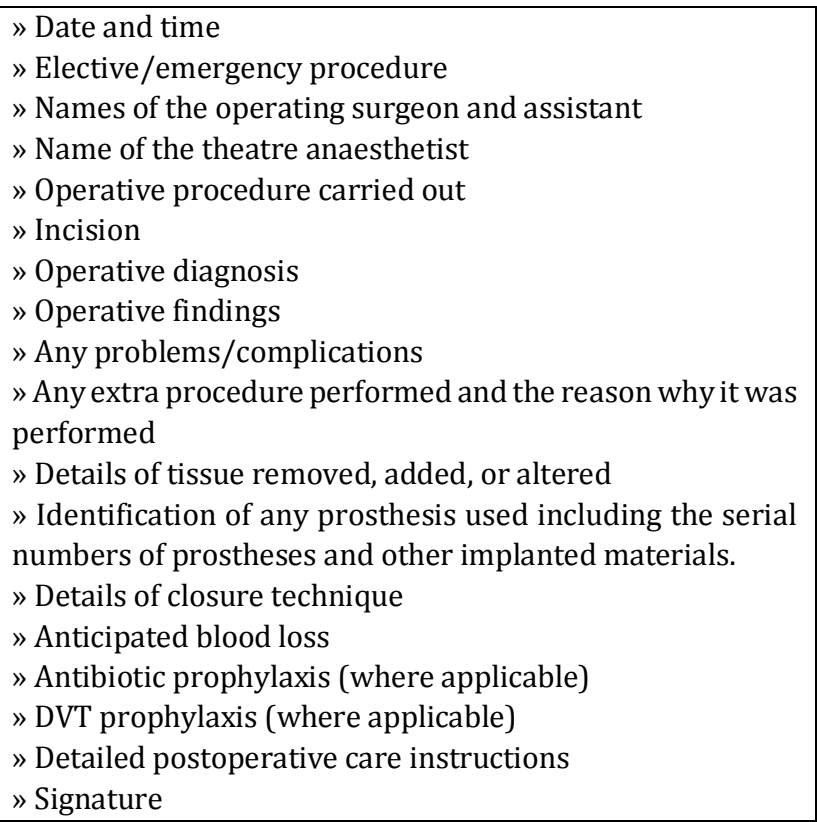

Table 2: Recommendations of Good Surgical Practice RCS England

\begin{tabular}{|c|c|c|c|}
\hline & $\begin{array}{c}\text { Hospital } \\
\text { A (N=30) }\end{array}$ & $\begin{array}{c}\text { Hospital } \\
\text { B (N=42) }\end{array}$ & $\begin{array}{c}\text { Hospital C } \\
\text { (N=30) }\end{array}$ \\
\hline Sex & 23 female & 34 Female & 26 Females \\
\hline Age in Years & $\begin{array}{c}38.70 \\
\text { (24 to 69 } \\
\text { years) }\end{array}$ & $\begin{array}{c}42.86 \\
\text { (17 to 79 } \\
\text { years) }\end{array}$ & $\begin{array}{c}41.29 \\
\text { (Range } \\
21 \text { to 70) }\end{array}$ \\
\hline $\begin{array}{c}\text { Mean Hospital } \\
\text { Stay }\end{array}$ & 2.78 & 2.68 & 3.24 \\
\hline $\begin{array}{c}\text { Indications: } \\
\text { Biliary Colic } \\
\text { Acute }\end{array}$ & & & \\
Cholecystitis & 20 & 34 & 22 \\
Gallstone \\
pancreatitis \\
Cholelithiasis
\end{tabular}

\begin{tabular}{|c|c|c|c|}
\hline & $\begin{array}{c}\text { Hospital } \\
\text { A } \\
\text { (n=30) }\end{array}$ & $\begin{array}{c}\text { Hospital B } \\
\text { (n=42) }\end{array}$ & $\begin{array}{c}\text { Hospital C } \\
\text { (N=30) }\end{array}$ \\
\hline Date and time & 30 & 42 & 30 \\
\hline $\begin{array}{c}\text { Operating Surgeon+ } \\
\text { Anaesthesia }\end{array}$ & 30 & 42 & 30 \\
\hline $\begin{array}{c}\text { Operating procedure } \\
\text { and diagnosis }\end{array}$ & 30 & 42 & 30 \\
\hline $\begin{array}{c}\text { Port } \\
\text { insertion/incision } \\
\text { sites }\end{array}$ & 30 & 42 & 30 \\
\hline $\begin{array}{c}\text { Method of creating } \\
\text { Pneumoperitoneum }\end{array}$ & Hassan=22 & Veress=6 $=42$ & Veress=26 \\
\hline $\begin{array}{c}\text { Introduction of trocar } \\
\text { under vision and no. } \\
\text { of ports }\end{array}$ & 20 & 42 & 20 \\
\hline Status of gallbladder & 16 & 36 & 18 \\
\hline $\begin{array}{c}\text { Dissection and } \\
\text { condition of Calot's } \\
\text { area }\end{array}$ & 22 & 38 & 24 \\
$\begin{array}{c}\text { Anatomical } \\
\text { abnormality }\end{array}$ & & & 1 \\
\hline
\end{tabular}

\begin{tabular}{|c|c|c|c|}
\hline $\begin{array}{c}\text { Identification and } \\
\text { dissection of cystic } \\
\text { duct and artery. clips } \\
\text { applies } \\
\end{array}$ & 25 & 37 & 28 \\
\hline Critical view of Safety & 16 & 34 & 8 \\
\hline $\begin{array}{l}\text { Removal from liver } \\
\text { bed, spillage of bile or } \\
\text { calculus }\end{array}$ & 16 & 26 & 10 \\
\hline $\begin{array}{c}\text { Method and port of } \\
\text { extraction }\end{array}$ & 16 & 30 & 15 \\
\hline $\begin{array}{c}\text { Removal of ports, } \\
\text { haemostasis, closure } \\
\text { of ports }\end{array}$ & 7 & 32 & 10 \\
\hline Duration of operation & 9 & 28 & 30 \\
\hline $\begin{array}{l}\text { Blood loss } \\
\text { Drain }\end{array}$ & $\begin{array}{l}17 \\
18\end{array}$ & $\begin{array}{l}39 \\
12\end{array}$ & $\begin{array}{l}12 \\
28\end{array}$ \\
\hline Diagram & 8 & $\begin{array}{l}26 \text { video } \\
\text { record } \\
\text { present in } \\
5 \text { cases. }\end{array}$ & $\begin{array}{l}0 \text { video } \\
\text { was } \\
\text { present in } \\
26 \text { cases. }\end{array}$ \\
\hline
\end{tabular}

\section{DISCUSSION}

With transition from open to laparoscopic cholecystectomy, there was a significant increase in the associated complications including those due to bile duct injuries. In this period, Strasberg and colleagues introduced the concept of "critical view of safety" for this to be achieved. The neck of the gallbladder must be dissected off the liver bed (i.e. the Calot's triangle is unfolded) to conclusively identify the two structures to be cut - the cystic duct and the cystic artery and traced where possible for confirmation. They classified the cause of bile duct injuries as either due to problems in technique or problems in misidentification; the operative note must make an attempt to rule out both possible errors. ${ }^{[8]}$

This is further documented either in the written note, intraoperative cholangiogram, or a photograph or video, if possible. [9,10] All patients in this study had paper based operative orders with boxes for individual pieces of information. Patient particulars and information deemed necessary as per RCS Eng Guidelines are rarely left unfilled.[6]

The information missing from the report and the various intraoperative events and information regarding deep vein thrombosis prophylaxis as mentioned in Table 4. Overall compliance of patient record with the standardised recommended laparoscopic cholecystectomy operative note is shown in Table 4 with regards to all the three hospitals.

Studies indicate that medical students and residents rarely receive formal instructions on postoperative note writing and frequently miss substantial information.[11] Wauben et al. in their survey study found that residents described more items than attending and were more likely to comply with the Dutch guidelines.[12]

The quality of operative note can be improved by formal instruction to the residents and medical officers in the beginning of rotation to include the basic components - name, time, procedure, incision, operative findings, blood loss, drains, and mode of closure along with significant anaesthesia events occurring during the operation. Each point can be further elaborated depending upon the intraoperative events or complications. ${ }^{[13]}$ 
Thomas et al. recommended standardization of paper or electronic notes with minimal standards in their urological practice.114] Similar notes can be standardised and used specifically for Laparoscopic Cholecystectomy and attached as a template either to the paper files or to electronic records.

Dukic et al. describes their implementation of commercial solution in their urology division, which also assisted in the management of waiting lists, perioperative care, and managing surgical inventories. Using this implementation, surgeon could create operation notes based on specialty specific or surgeon specific operation template as well as they found substantial improvement in operation notes in comparison to handwritten notes especially in complex urological operations.[15]

Accuracy and completeness of operative note is considered essential, but as in this study, it is often incomplete or not up to the prescribed standard. In their comparison study, Harvey et al. advocate the use of standardised operative report resulted in more complete and reliable interpretable data, which could be more quickly accessed.[16] Narrative-based paper reports do miss many points, which might be regarded as important as in our study. As can be seen in table 3 , there were multiple deficiencies in the operative note. Notable deficiency is the lack of comment on cystic duct and cystic artery dissection. Further missing from the records were blood loss figures and time taken to complete the procedure $(n=35)$. In this study, we have not included the disposition of removed gallbladder, use of preoperative antibiotics, prophylaxis against DVT etc. which are noted in place other than the operative note, but are essential part of the operation.

Hospital B where most of the notes are written by surgical resident or junior consultant had more detailed description and more likely to comment on demonstration of "critical view of safety" whereas hospital C much less likely to include description of the "CVS" though the dissection and clipping were described properly. This could be due to individual consultant preference and the importance they attach to the individual step. In teaching hospital, residents are more likely to supervised by multiple consultants and hence the notes were better and more detailed overall though there is no formal training on operation notes.[11] In our institutions, the operative notes are usually written immediately following the operation by one of the team members; usually the junior resident and there should be minimal distortion due to time lapse unlike one the descriptions of inadequate note described by Wauben et al. [12] What affects the quality of notes is the pertinent points considered important and subsequently mentioned in the charts.

The provision of template or black box concept of generation of operative note would be highly beneficial in our work environment. In a comparative study by Edhemovic et al. on record of rectal cancer operations found computerised template-based record to be more thorough, quicker to complete, and easier to extract data as compared to narrative record.[17] This has been adapted for use in other surgeries as well.

As commented upon by Wauben et al. even in conditions where the surgeons are writing operative note for review; many points are missing from the report.[12] The conclusion that can be drawn is that this omission is not due to lack of time or effort, but an unawareness regarding the salient points to be included or emphasised. Possibly in a simple uneventful case, the surgeon does not deem it necessary to mention fine details as compared to one in which there was a complication or the surgeon encountered difficulties. In such cases, a format, which provides option to write freely would be helpful. Stewart et al. found no apparent relationship between the level of difficulty of the operation and the extent of the descriptions of the key elements. They advocate that Cognitive Task Analysis (CTA) should be used for writing operative notes and their data show that the step (in the operative report) that most separated the complicated cases from the uncomplicated cases was a description of a complete dissection of the lateral and inferior regions of the Calot's triangle (i.e., the medial surface of the gallbladder infundibulum and the upper margin of the cystic duct).[2]

Thomson et al. find that introduction of procedure-specific proforma to assist in note writing can result in much better capture of general and procedure-specific information result in more robust notes.[13]Introduction of separate form for each procedure will be logistically difficult. Computerised formats are more practicable as it can be utilised in all operations with procedure-specific alteration, but requires associated infrastructure and initial investment.

\section{LIMITATIONS}

This is a preliminary observational study with limited number of patients. A study following after awareness and use of standardised paper or electronic format operative report would be helpful.

\section{CONCLUSION}

Handwritten operations notes are subject to high degree of variations with regards to level and details of information provided and may occasionally be illegible. Technically complete operative report may lack details of operative events, which is clinically relevant. Residents and junior consultants were more likely to describe steps in details as compared to senior consultants. Furthermore, difficult operations were more likely to contain detailed steps in comparison with straight forward cases where the whole note consisted of just 5-6 lines.

Use of templates or computer-based notes would be very helpful, which can be adapted for use in other operations as well.

Laparoscopic cholecystectomy operative notes do not always comply with the minimum standards required. This can influence future patient management and of limited use in retrospective research besides having medicolegal implications.

\section{REFERENCES}

1. Kapoor VK. Medicolegal aspects of bile duct injury. J Min Access Surg 2016;12(1):1-3.

2. Stewart L, Hunter JG, Wetter A, et al. Operative reports: form and function. Archives of Surgery 2010;145(9): 865-71.

3. Shea JA, Healey MJ, Berlin JA, et al. Mortality and complications associated with laparoscopic cholecystectomy a meta-analysis. Annals of surgery 1996;224(5):609-20. 
4. Bianco FJ, Riedel ER, Begg CB, et al. Variations among high volume surgeons in the rate of complications after radical prostatectomy: further evidence that technique matters. J Urol 2005;173(6):2099-103.

5. Din R, Jena D, Muddu BN. The use of an aide-memoire to improve the quality of operation notes in an orthopaedic unit. Ann Royal Coll Surg Engl 2001;83(5):319-20.

6. Good surgical practice - Royal College of Surgeons of England http://www.rcseng.ac.uk/surgeons/surgicalstandards/professionalism-surgery/gsp/gsp 2016.

7. Lange JF, Stassen LPS. Best practice: De techniek van de laparoscopische cholecystectomie (critical view of safety; werkgroep endoscopische chirurgie van de nederlandse vereniging voor heelkunde) 2006:1-8.

8. Strasberg SM. Avoidance of biliary injury during laparoscopic cholecystectomy. Journal of hepatobiliary pancreatic surgery 2002;9(5):543-7.

9. Plaisier PW, Pauwels MM, Lange JF. Quality control in laparoscopic cholecystectomy: operation notes, video, or photo print? Hpb 2001;3(3):197-9.

10. Buddingh KT, Morks AN, ten Cate Hoedemaker HO, et al. Documenting correct assessment of biliary anatomy during laparoscopic cholecystectomy. Surgical endoscopy 2012;26(1):79-85.
11. Gillman LM, Vergis A, Hardy K, et al. Resident training and the dictated operative report: a national perspective. Canadian Journal of Surgery 2010;53(4):246-50.

12. Wauben LS, Goossens RH, Lange JF. Differences between attendings' and residents' operative notes for laparoscopic cholecystectomy. World Journal of Surgery 2013;37(8):1841-50.

13. Wauben LS, Goossens RH, Lange JF. Evaluation of operative notes concerning laparoscopic cholecystectomy: are standards being met? World Journal of Surgery 2010;34(5):903-9.

14. Thomson DR, Baldwin MJ, Bellini MI, et al. Improving the quality of operative notes for laparoscopic cholecystectomy: assessing the impact of a standardised operation note proforma. International Journal of Surgery 2016;27:17-20.

15. Dukic I, Vissamsetti B, Payne S. Improving the quality of operation notes. BJU international 2011;107(10):1546-8.

16. Harvey A, Zhang H, Nixon J, et al. Comparison of data extraction from standardised versus traditional narrative operative reports for database-related research and quality control. Surgery 2007;141(6):708-14.

17. Edhemovic I, Temple WJ, DeGara CJ, et al. The computer synoptic operative report-a leap forward in the science of surgery. Annals of Surgical Oncology 2004;11(10):941-7. 